\title{
Evaluation of the optimal activation parameters for almond shell bio-char production for capacitive deionization
}

\author{
Maniscalco M. P. ${ }^{1,3}$ Corrado C. ${ }^{2}$,Volpe R. ${ }^{3}$ and Messineo A. ${ }^{1 *}$ \\ ${ }^{1}$ Faculty of Engineering and Architecture, Kore University of Enna, Cittadella Universitaria, \\ 94100 Enna, Italy \\ ${ }^{2}$ Department of BioMedicine, Neurosciences and Advanced Diagnostics (Bi.N.D), Via Divisi \\ 83, 90133 Palermo, Italy \\ ${ }^{3}$ School of Engineering and Materials Science, Queen Mary University, London, United \\ Kingdom
}

\begin{abstract}
A study on a possible new biomass waste to be used as electrode material for capacitive deionization (CDI) processes was performed. Raw almond shells were pyrolyzed at 800, 900 and $1,000{ }^{\circ} \mathrm{C}$ and then activated through $\mathrm{CO}_{2}$. Carbon activation is used to develop porosity inside the material, increasing the specific surface area and the adsorption performances. In this work, authors tried to correlate the effects of pyrolysis and activation temperature on the ion storage capacity. Results from the desalination tests indicated that the best performance in terms of ion adsorption was obtained when the bio-char was activated at the temperature of $900{ }^{\circ} \mathrm{C}$. Brunauer-Emmet-Teller (BET) and Barret-Joyner-Halenda (BHJ) analysis confirmed the trend of the CDI tests, reporting the highest surface area and share of micropore sites for the $900{ }^{\circ} \mathrm{C}$ samples. Salt adsorption capacity was found to be in the range of 13.7 to $19.2 \mathrm{mg}$ $\mathrm{g}^{-1}$.
\end{abstract}

\section{Keywords}

Biomass; Almond shell; Carbon activation; Capacitive deionization.

\section{Introduction}

Fresh water supply is one of the most discussed issues of the last decades (Chen et al., 2011; Z. Chen et al., 2018). On daily basis, almost 100 millions of cubic meters of sea and brackish water need to be desalinated to match the demand for municipal and industrial purposes (Zarzo

${ }^{*}$ Corresponding author. Tel: +390935 536448;

E-mail address: antonio.messineo@unikore.it (A. Messineo). 
and Prats, 2018). Most of the desalination plants relies on the reverse osmosis technology, followed by the thermal distillation processes (AlMarzooqi et al., 2014). One of the main drawbacks of these system is the environmental pollution due to the energy production to satisfy the plant demand. In fact, as referred by the Global clean water desalination alliance, approximately 76 million tons of $\mathrm{CO}_{2}$ are yearly generated worldwide, to produce fresh water from salty sources. It results, therefore, imperative the need of reduce the energy consumption during desalination, in order to mitigate its relative environmental impact. For these reasons, there is an increased attention toward the research of a more eco-friendly approach. Capacitive deionization (CDI) is gaining increased attention due to the potential lower energy consumption when treating brackish water and to the possibility of using waste biomass as precursor for the realization of activated carbons (Chérif et al., 2015; Huyskens et al., 2013; Porada et al., 2013). The analysis conducted by Anderson and his research team (Anderson et al., 2010) showed promising perspective for brackish water desalination through capacitive deionization. To evaluate the process efficiency, authors applied the concept of cycle efficiency used for supercapacitors to the capacitive deionization process, calculating it as the ratio between the recovered energy during discharge and the one spent in charging. The minimum thermodynamic energy needed to remove salt ions from water is known to be approximately $1.1 \mathrm{kWh} \mathrm{m}^{-3}$ and $0.12 \mathrm{kWh} \mathrm{m}^{-3}$ respectively for sea and brackish water. According to the thermodynamic model proposed by Anderson (Anderson et al., 2010) if CDI can achieve a cycle efficiency of $60-70 \%$, it could become an energetically competitive technology for brackish water desalination. Tests conducted by Welgemoed and Shutte (Welgemoed and Schutte, 2005), reported a round efficiency of approximately 50\%, but further improvements could be achieved by increasing the efficiency of the energy recovery process.. CDI relies on porous material, like activated carbons, carbon nanotubes or carbon fibers, that electrostatically trap and store salt ions from a brackish water flow, thanks to a voltage difference applied between two electrodes. By inverting the voltage or short-circuiting the system, electrodes can be regenerated, discharging the ions in a bulk solution ( $\mathrm{Li}$ et al., 2016; Oren, 2008). To be effective in ion sequestration, electrode material must guarantee specific intrinsic properties. In fact, an high surface area, a proper pore distribution, a good electrical conductivity and a good permeability must be guaranteed (Dehkhoda et al., 2016a, 2016b). Both biomass recovered material and artificial porous media, was tested in the last years by numerous research groups (Belaustegui et al., 2018; El-Deen et al., 2014; Zhang et al., 2007). If artificial material on one hand allows to develop a proper structure that boost ion adsorption, one the other hand the very delicate and expensive process to realize them limit the diffusion (Anderson 
et al., 2010; Oren, 2008). Waste biomass sources can significantly reduce the cost of the activated carbon production, but a lower adsorption capacity must be expected. Different kind of biomasses (P.-A. Chen et al., 2018; Feng et al., 2018; Hou et al., 2015; Lado et al., 2017; Li et al., 2016), as well as carbon nanotubes had been tested during the last years. Waste biomass activated carbons are more and more investigated due to the low prices and the great abundance of the starting materials. Among the best results of the tested biomasses, Feng and his research group (Feng et al., 2018) realized and tested activated carbons made from Loofa sponge achieving a salt adsorption capacity of $22.5 \mathrm{mg} \mathrm{g}^{-1}$, with an applied voltage between the electrodes of 1V. Similarly, Li and his co-workers (Li et al., 2016) tested the activated carbon produced from cotton waste in a capacitive deionization cell with an applied voltage of $1.2 \mathrm{~V}$, resulting in an adsorption capacity of $16.1 \mathrm{mg} \mathrm{g}^{-1}$. Lower salt removal capacity $\left(5 \mathrm{mg} \mathrm{g}^{-1}\right)$ was reported by Lado et al. (Lado et al., 2017) when using activated carbon made from sugar cane fly ashes, with an applied voltage of $1.2 \mathrm{~V}$. Moreover, the synthesis of artificial porous media starting from polymeric structures, is a very delicate and expensive process compared to the one involving residual.

In the present paper, different pyrolysis and activation temperatures were tested for the production of activated carbons from almond shells, in order to study the evolution of the material structure and adsorption capacity. For what is the authors' knowledge no previous tests were conducted on the use of almond shells as precursors material for the electrode fabrication in CDI applications. The aim of the work is to gain information on how this kind of biomass behave and how the activation temperature affect the carbon structure and its adsorption capacity. Physical activation was preferred over chemical one since it can guarantee a good surface area and pore size distribution, without the drawback of dealing with chemical waste. The analysis conducted on the saturated electrodes allowed also to evaluate the adsorption capacity in relation to the internal carbon structure, opening to a new field of possible research on carbon structure for CDI.

\section{Materials and methods}

\subsection{Preparation of the activated carbons}

Fresh almond shells were collected already dry and stored for further use. Once needed, the almond shells were grinded through a miller (Retsch ZM 200; Germany) and sieved (Retsch AS 200; Germany) in order to obtain particles size lower than $125 \mu \mathrm{m}$, dried again in oven at 
$90{ }^{\circ} \mathrm{C}$ for $60 \mathrm{~h}$ and then stored at the temperature of $-20{ }^{\circ} \mathrm{C}$ in Argon atmosphere. For the production of the activated carbon, a Carbolite tubular furnace (Carbolite Gero 3216CC Controller; UK) with $\mathrm{Ar}, \mathrm{N}_{2}$ and $\mathrm{CO}_{2}$ gas feed was used. The biomass was displaced in a ceramic crucible of approximately $30 \mathrm{~cm}^{2}$, with thickness of the bed of $1.5-2 \mathrm{~mm}$. The crucible was then placed in the centre of the furnace and Ar was fluxed at $2 \mathrm{~L} \mathrm{~min}^{-1}$ for $10 \mathrm{~min}$ to ensure an inert environment inside the reactor, before starting the pyrolysis. Biomass was then carbonized at 800,900 and $1000{ }^{\circ} \mathrm{C}$ at a heating rate of $10{ }^{\circ} \mathrm{C} \mathrm{min}{ }^{-1}$ under an Argon flow of 1.2 $\mathrm{L} \mathrm{min}^{-1}$. Once the peak temperatures were reached, chars were firstly carbonized for $10 \mathrm{~min}$ in Argon and then activated by switching to $\mathrm{CO}_{2}$ for $15 \mathrm{~min}$, keeping the same flow rate as before. Once the process was finished, the furnace was let to cool down to ambient temperature in Argon atmosphere and activated carbons were weighted and stored. The samples obtained were named AC800, AC900 and AC1000 respectively for the ones produced at 800, 900 and $1000{ }^{\circ} \mathrm{C}$.

\subsection{Preparation of the electrodes}

Activated carbons were used to prepare the carbon electrodes for the CDI experiments. ACs were initially mixed with polyvinylidene fluoride (PVDF-Sigma Aldrich 24937-79-9; Missouri, USA) in a ratio of 9:1 (w/w) for 5 minutes using mortar and pestle. Once an homogeneous matrix was obtained, N-Methyl-2-pyrrolidone (NMP-Sigma Aldrich 872-50-4; Missouri, USA) was added and mixed for further 20 minutes to dissolve the binder and obtain a slurry of the desired consistence. To produce the electrodes, the carbon paste was coated on a current collector (MTI Corporation - EQ-CC-Al-18u-260; California, USA) using a wire bar (K-hand coater) and then shaped to the desired dimensions (42 mm X 27mm ). Electrode thickness was calculated to be approximately $130 \mu \mathrm{m}$. The carbon paste was dried in oven at $80{ }^{\circ} \mathrm{C}$ for $72 \mathrm{~h}$ and then weighted and stored. The mass of each electrode was calculated by weight difference between the dried electrode and the current collector and was equal to 0.06 g.

\subsection{Material characterization}

Morphology and structure of the activated carbon produced were studied with the Scanning Electron Microscope (SEM FEI Inspect-F; Oregon, USA) and the Transmission Electron Microscope (TEM JEOL 2010; Japan), while for the chemical composition the study of Energy

Dispersive Spectroscopy (EDS) spectra was performed. Specific surface area and pore size distribution were evaluated through Brunauer-Emmet-Teller (BET) and Barret-Joyner- 
Halenda $(\mathrm{BJH})$ analysis with Nova 4200e (Austria). SEM was also used to investigate the changes in the surface structure between the activated carbons and the produced electrodes, to check whether the use of the binder caused changes in the morphology of the samples. For this purpose, saturated electrodes were dried in oven at $95{ }^{\circ} \mathrm{C}$ to $72 \mathrm{~h}$ and then crushed again to obtain a carbon powder.

\subsection{Electrodes testing}

Electrodes were tested in a CDI cell. For each type of activated carbons, two different electrodes pairs were made and tested. Before starting the adsorption test, the cell was assembled and deionized water was fluxed for $2 \mathrm{~h}$ to remove any detachable particles from the electrode surface that could otherwise influence the following measurements. For the desalination tests, it was continuously recirculated a $50 \mathrm{ml}$ of a $500 \mathrm{mg} \mathrm{L}^{-1} \mathrm{NaCl}(>99 \%$, SigmaAldrich; Missouri, USA) solution at a flow rate of $10 \mathrm{ml} \mathrm{min}^{-1}$ from the main becker to the cell, by means of a peristaltic pump (Watson Marlow 323; UK). Between the two electrodes it was applied a voltage difference of $1.2 \mathrm{~V}$, ensured by a power supply (EA 3048b; Germany), and the salt concentration was continuously measured inside the becker by means of a conductivity meter (Reed SD-4307 Conductivity/TDS/Salinity Datalogger; USA). Adsorption tests lasted $120 \mathrm{~min}$ and the salt adsorption capacity (SAC) of each electrodes pair was evaluated through equation 1:

$S A C=\frac{\left(C_{i n}-C_{f i n}\right) * V}{m_{e l}} \quad\left[\mathrm{mg} \mathrm{g}^{-1}\right]$ Eq. 1

Where:

$\mathrm{Ci}_{\mathrm{n}}$ is the initial salt concentration in $\mathrm{mg} \mathrm{L}^{-1}$

$\mathrm{C}_{\text {fin }}$ is the final salt concentration in $\mathrm{mg} \mathrm{L}^{-1}$

$\mathrm{V}$ is the solution volume in $\mathrm{L}$

$\mathrm{m}_{\mathrm{el}}$ is the total electrode mass in $\mathrm{g}$

\section{Results and discussion}

\section{Morphology and structure of the activated carbons}

Pyrolysis and activation led to a mass loss in the samples due to the removal of most of the volatile compounds (Volpe et al., 2017). The mass yields of the produced activated carbon were calculated once the carbons had cooled down to room temperature, and were found equal 
to $27 \%, 24 \%$ and $24 \%$ respectively for AC800, AC900 and AC1000. The morphological analysis conducted with the SEM showed the presence and the formation of pores on the external surface of the material as well as bubbling phenomena, possibly due to deposition or melting (Volpe et al., 2015). The bubbling phenomena increase the pores dimension of the material, improving the mass transport. As long as pyrolysis proceed, the generated volatile matter remain confined inside the particle, forming bubbles (Yu et al., 2007). The larger the particle, the harder is for the activating agent to diffuse inside and develop porosity, as well as for the produced gases to escape from the particle core. Once the bubble reach the surface, it explode releasing the volatiles. The whole process is known to further increase the porosity of the material (Valdés et al., 2018).

On the external surface, there were found pores with diameter in the range of 10-35 $\mu \mathrm{m}$ which can act as main pathways to reach the micro and nanopores in the inner part of the activated carbon, as also referred in (Fukuyama et al., 2001; Martínez et al., 2006; Zabaniotou et al., 2008). In Fig 1 a-e it can be seen the pores development on the outer surface of the samples (Fig $1 \mathrm{c}$ ) as well as an increase in the pore diameter of the already existing holes and a reduction of the thickness of the external wall of the particles, possibly due to the shrinking phenomena and the removal of volatile compounds.

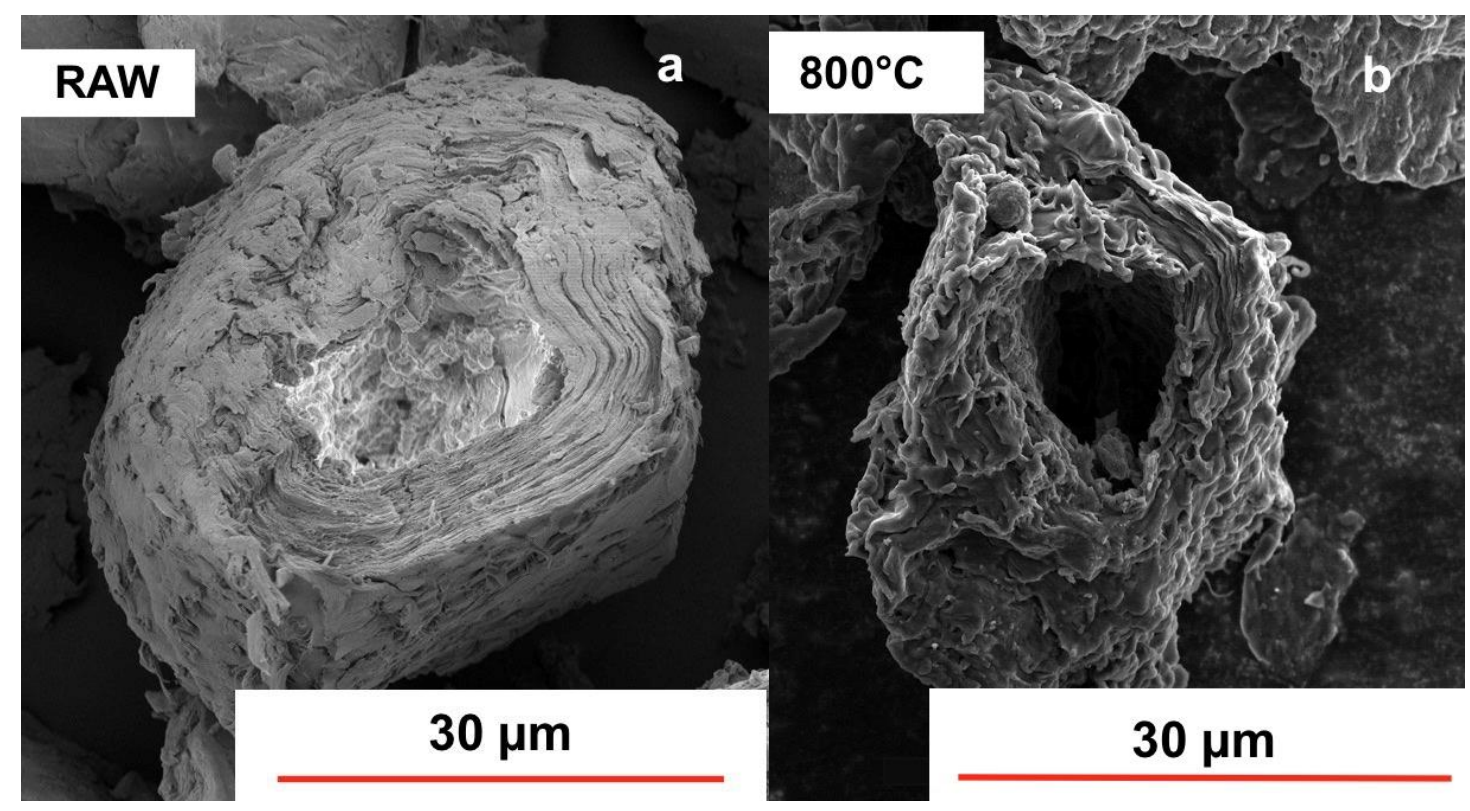




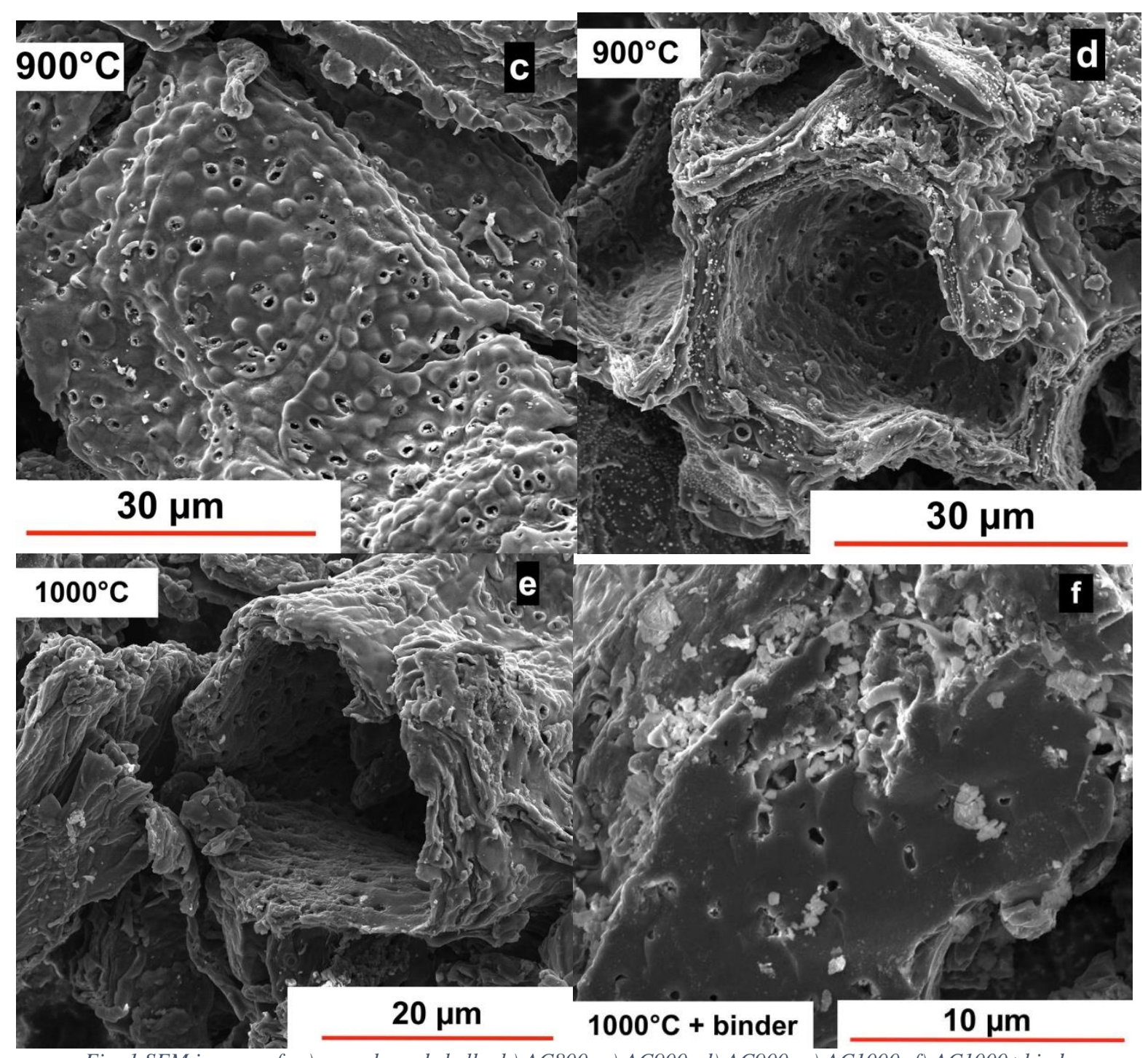

Fig. 1 SEM images of: a) raw almond shells; b) AC800; c) AC900; d) AC900; e) AC1000; f) AC1000+binder.

The already existing holes in the raw material present diameter in the range of 15-17 $\mu \mathrm{m}$, while in the activated carbons it is increased up to $30-35 \mu \mathrm{m}$. The role of $\mathrm{CO}_{2}$ in carbon activation and pore structure development was already investigated by Rodriguez-Reinoso and his coworker for the production of activated carbon from peach stones (Rodriguez-Reinoso et al., 1992). Authors found that the action of $\mathrm{CO}_{2}$ is more evident as long as the activation temperature increase, when performing pyrolysis and activation at temperatures within $850{ }^{\circ} \mathrm{C}$. As also reported by Kennedy and his co-workers (Kennedy et al., 2005), during pyrolysis most of the volatile compounds are released from the biomass, creating new holes in the structure while part of the cellulose and lignin are converted into carbon. However, some of the volatiles produced during pyrolysis might re-polymerize and condensate on the external surface of the chars clogging part of the existing pores. The following physical activation stage is needed to remove the tar deposit as well as reopening the blocked pores and create new ones (Pallarés et 
al., 2018). The reducing atmosphere, due to the presence of $\mathrm{CO}_{2}$, mostly for temperatures above $700{ }^{\circ} \mathrm{C}$, lead to a partial gasification according to the reverse of the Boudouard reaction (eq. 2), increasing the adsorption capacity of the material.

$$
\mathrm{C}+\mathrm{CO}_{2} \rightarrow 2 \mathrm{CO} \text { eq. } 2
$$

The investigation conducted on the surface of the activated carbon mixed with binder (Fig. 1f), showed a partial pore occlusion due to binder deposition on the outer carbon surfaces. To gain information on the surface composition, it was performed an EDS analysis on the AC1000 electrode, to get an overview of the chars composition. The surveys on the external surface reveal a sample composition made of $83.4 \%$ of carbon, $11.1 \%$ of oxygen, $3.1 \%$ of fluorine, $1.7 \%$ of sodium and $0.6 \%$ of aluminium, based on weight. The presence of fluorine is strictly due to the use of the binder. Moreover, it was also observed a significant evolution in the internal structure of the three different carbons. The formation of graphitic layers can clearly be seen in AC800 (white circular spots in Fig 2a,b) together with a broader area of amorphous carbon. Graphite layers present spacing in the range of $0.13-0.33 \mathrm{~nm}$, which could be due to different orientation of the crystals. In fact, the measure of $0.13 \mathrm{~nm}$ could be relative to the distance in the carbon covalent bonds while, being the reported distance for graphite planes equal to $0.34 \mathrm{~nm}$, the measurement of $0.33 \mathrm{~nm}$ could be a good approximation of this case. Fig $2 \mathrm{c}$ reveals a more uniform internal structure for AC900 with respect to the other two samples. No evidences of graphitic layers were found even if, since they were spotted in the other carbons, there should be present in the material.

AC1000 (Fig 2d) presents onion rings structure characteristic of the carbon cluster formation (Hoekstra et al., 2015) with outer diameters of the rings in the range of 15-25 nm, and an internal diameter of approximately $9 \mathrm{~nm}$. The number of layers was between 11 and 14, within all the onions-shaped formations,. The increase in pyrolysis temperature induced significant changes in the internal structure of the material, increasing the degree of graphitization. Similar considerations were proposed by Guizani and his research group (Guizani et al., 2017), which found that for pyrolysis temperature above $600{ }^{\circ} \mathrm{C}$, graphene-like structures were generated due the crystallization of the polyaromatic compounds released during the process.

These particular constitutions, increasing in size, lead toward a transformation of the amorphous phase to more ordered graphitic-like structure (Debiagi et al., 2018). Also Billaud 
et al. (Billaud et al., 2016) found an increase in soot formation from $800^{\circ} \mathrm{C}$ with a steep increase for temperature above $1000{ }^{\circ} \mathrm{C}$.

The formation of soot particles for temperatures above $1000{ }^{\circ} \mathrm{C}$ was confirmed by Quin and his research group (Qin et al., 2012), as well as by Wang et al (Wang et al., 2018). In (Wang et al., 2018) authors refer of a linear increase in soot yield, on weight, from $0.47 \%$ to $5.95 \%$ when the pyrolysis temperature of wheat straw was raised from $1000{ }^{\circ} \mathrm{C}$ to $1200{ }^{\circ} \mathrm{C}$, while no trace was found in the sample pyrolyzed at $900{ }^{\circ} \mathrm{C}$. The process of soot formation is still under discussion among the scientific community. One of the of possible the pathways of sooth growth on which many researchers agree on is the nucleation starting from polycyclic aromatic hydrocarbons (PAH), even though the process in detail is not yet fully understood (D'Anna, 2009; Debiagi et al., 2016; Frenklach and Mebel, 2020; Wang and Chung, 2019). During biomass pyrolysis the released PAH from the decomposition of lignin, bonding and growing in size lead to the nucleation of soot particles. A detailed discussion of soot formation was proposed by Franklach and Mabel in (Frenklach and Mebel, 2020).
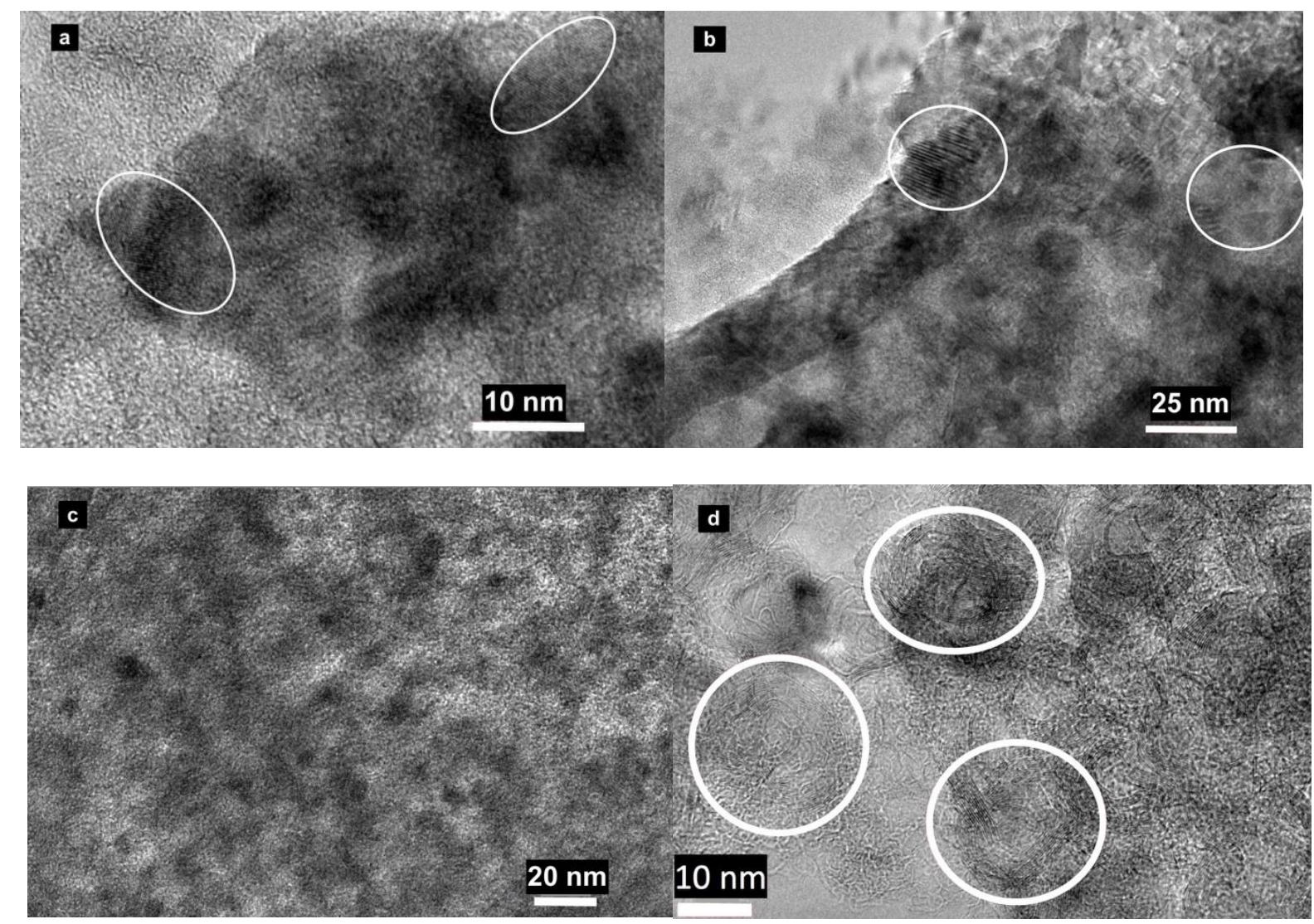

Fig. 2 TEM images of a,b) AC800, c) AC900 and d) AC1000.

Surface area and pore size distribution analysis 
The analysis of the specific surface area and the pore size distribution of the three samples revealed an increase in the porosity when raising the activation temperature from $800{ }^{\circ} \mathrm{C}$ to $900{ }^{\circ}$ C. In Fig. 3 and Fig. 4 are reported the curves of the adsorbed gas volume and the cumulative surface area for AC800, AC900 and AC1000. When the activation temperature is increased from $800{ }^{\circ} \mathrm{C}$ to $900{ }^{\circ} \mathrm{C}$, the specific surface area is almost doubled, raising from $226.3 \mathrm{~m}^{2} \mathrm{~g}^{-1}$ to $452.2 \mathrm{~m}^{2} \mathrm{~g}^{-1}$.

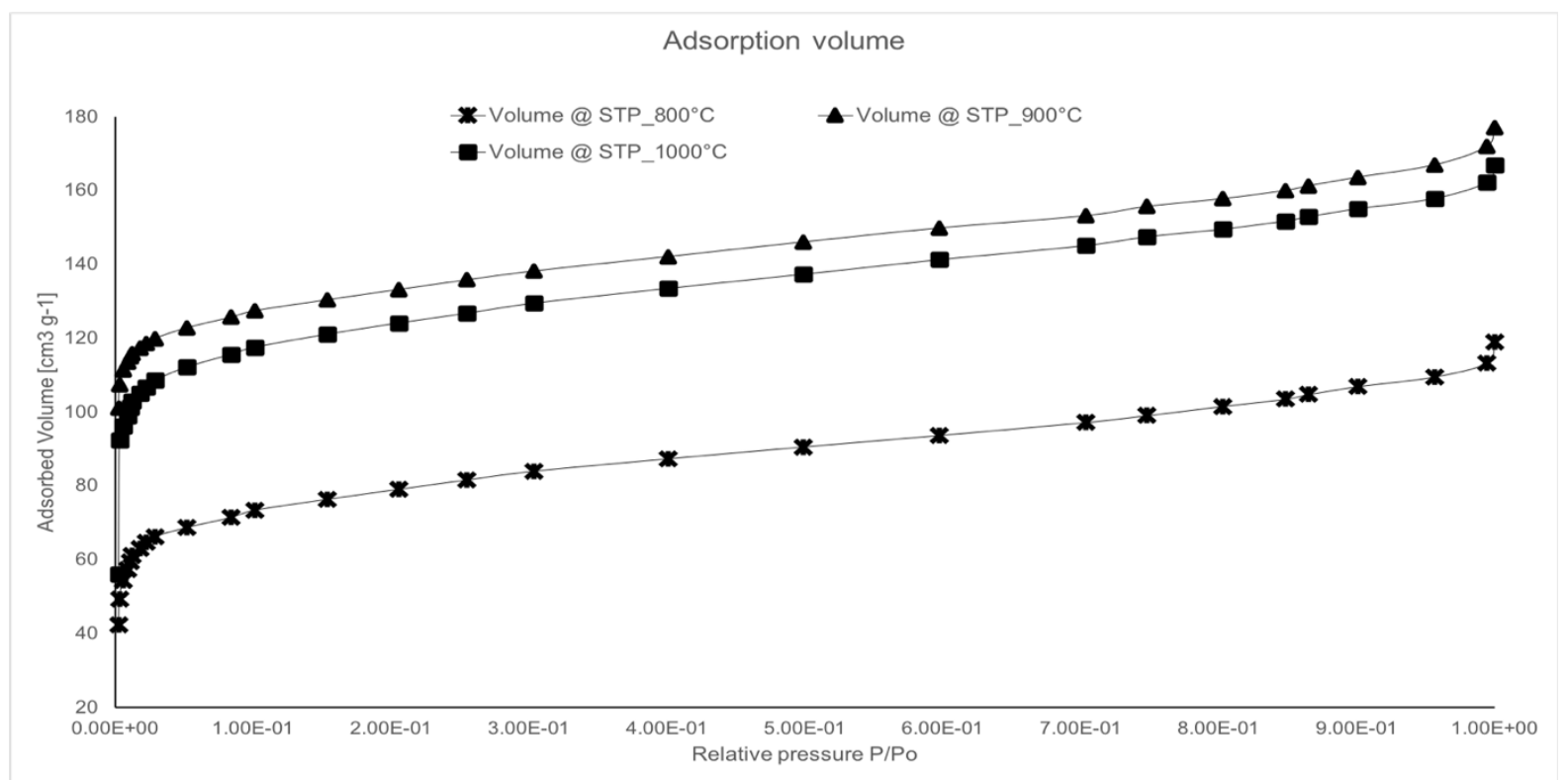

Fig. 3 Adsorption volume for AC800, AC900 and AC1000.

A further increase in the activation temperature up to $1000^{\circ} \mathrm{C}$ led to a reduction in the specific area of almost $30 \%$, reaching $317.4 \mathrm{~m}^{2} \mathrm{~g}^{-1}$. All the three curves present the classic behaviour of the Type 1 isotherm, according to the IUPAC classification, with an steep increase in the absorbed volume for relative pressure $<0.2 \mathrm{P} / \mathrm{P}_{0}$, followed by steady increment until $\mathrm{P} / \mathrm{P}_{0}=$ 0.9. The initial part of the adsorption curve represents the contribution of micro-porosity to the total surface area, which it can clearly be see that result predominant in all of the three activated carbon samples. the second branch of the curve is characterized by an almost flat trend, indicating the lack of larger pores in the material. 


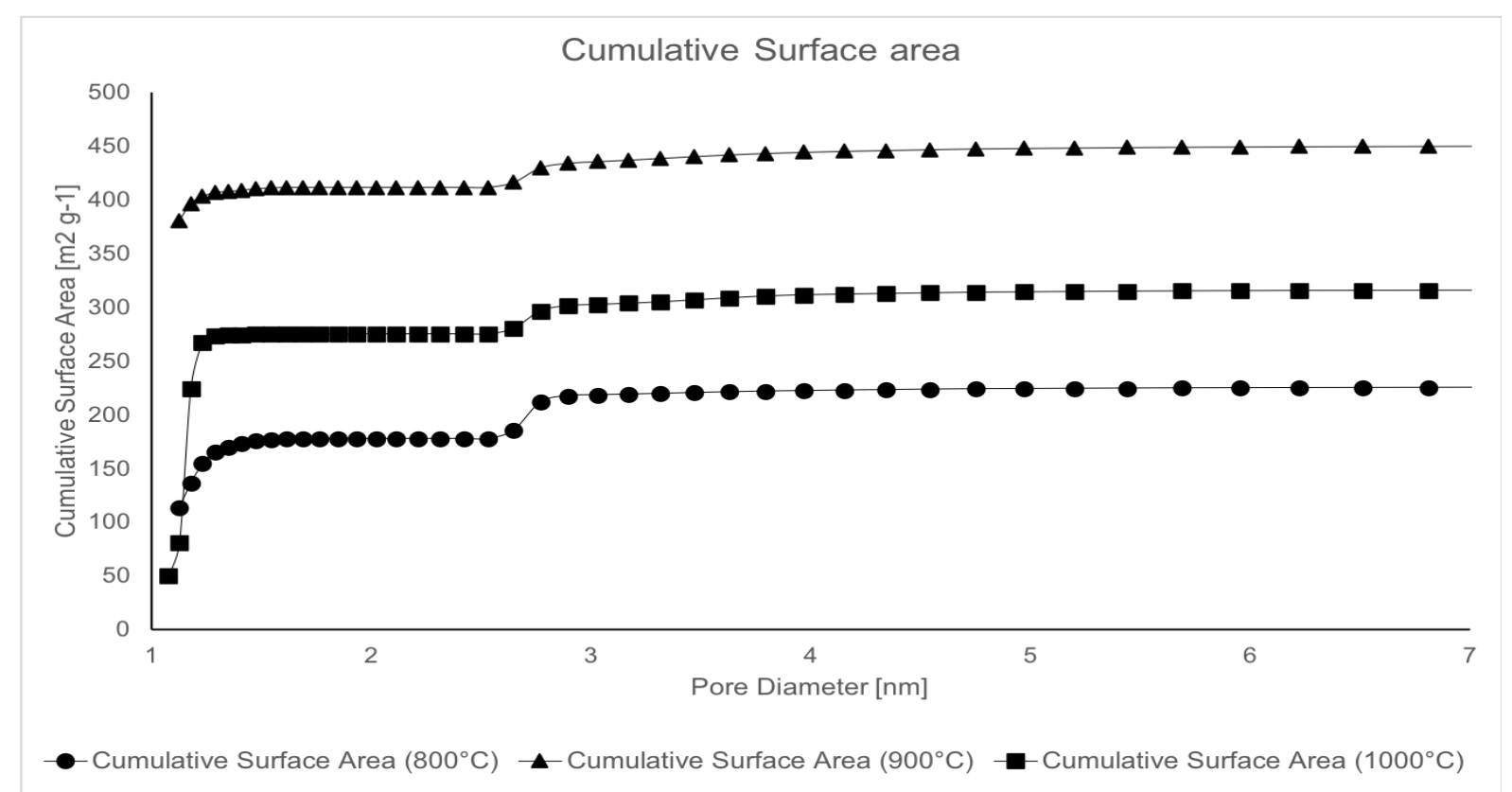

Fig. 4 Cumulative Surface Area for AC800, AC900 and AC1000.

In terms of volume of gas adsorbed, the difference between AC900 and AC1000 is lower than for the cumulative surface area, presenting a 5.5\% decrease from 177 to $167 \mathrm{~cm}^{3} \mathrm{~g}^{-1}$, while for AC800 was $118 \mathrm{~cm}^{3} \mathrm{~g}^{-1}$. The study of the pore size distribution reveals also a significative change in the pore development inside the activated carbons (Fig.5).

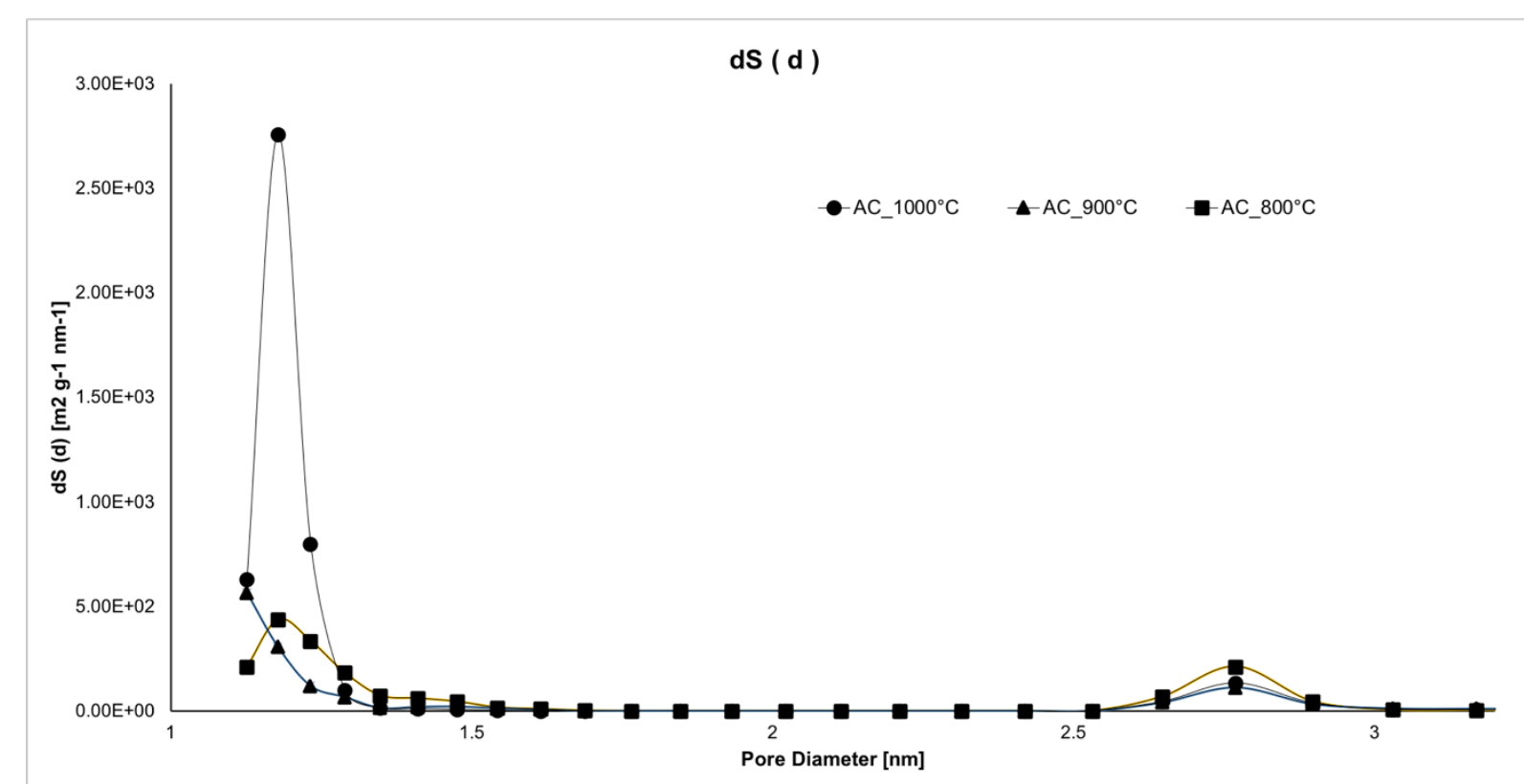

Fig. 5 Pore size distribution for AC800, AC900 and AC1000

Comparing the results reported in Fig. 5 with the ones in Fig. 4, it can be noticed that the share of micropores with diameter $<1 \mathrm{~nm}$ change significantly when varying the activation temperature. Indeed, while for AC1000 only $16 \%$ of the pores present diameters $<1 \mathrm{~nm}$, for 
AC800 is $50 \%$ while for AC900 it raises up to $84 \%$. These results could indicate a variation in the carbon structure when changing the activation temperature. In fact, the analysis reported showed a non-linear correlation between the increase in the activation temperature and the increase in surface area and micropore development. This could be due to the higher degree of carbonization, as also confirmed by the TEM images, which could imply a re-organization of the internal structure as well as a widening of the already existing pores.

Similar results were also reported in (Dehkhoda et al., 2014) for carbon activation in the temperature range of $675-1,000{ }^{\circ} \mathrm{C}$ due to micropore collapse when reaching the highest temperature and the formation of a more ordered structure. Micropore enlargement at high temperature due to pore walls collapse was also reported by Zhang and his co-workers (Zhang et al., 2004) when activating agricultural residues through $\mathrm{CO}_{2}$. Authors also reported an increase in the severity of the phenomena as long as the activation time increase. Increase in surface area for temperature range of $500-900{ }^{\circ} \mathrm{C}$ were also reported by Lua and Gou when testing activation of oil palm shell (Lua and Guo, 2001). Authors found a raise in surface area for the $900{ }^{\circ} \mathrm{C}$ sample when the activation time was kept within $30 \mathrm{~min}$, while a significant decrease was encountered when char was maintained under $\mathrm{CO}_{2}$ for $60 \mathrm{~min}$. This result, according to the authors, was related to a strong interaction in the $\mathrm{CO}_{2}$-carbon reaction.

\section{Salt adsorption capacity}

Electrode testing was conducted with an initial salt concentration of $500 \mathrm{mg} \mathrm{L}^{-1}$ and an applied voltage of $1.2 \mathrm{~V}$. Each adsorption test was run in duplicate and the average of the two different runs was also reported in the graphs of Fig. 6. For all the three samples, the saturation of the electrodes was reached after 120 minutes from the beginning of the tests. AC900 showed the best salt adsorption capacity, with up to $19.2 \mathrm{mg}$ of adsorbed salt for each gram of electrode material, while AC800 and AC1000 reached 14.6 and $13.7 \mathrm{mg} \mathrm{g}^{-1}$, respectively. The obtained results are in line with the micro-porosity development of the three different samples. Indeed, it is well established that ion storage is mostly performed inside the pores with diameter lower than $1 \mathrm{~nm}$ (Dykstra et al., 2016; Li et al., 2017; Zhang et al., 2019). In fact, despite the higher surface area of AC1000 with respect to AC800, the lower amount of micropore sites could determine an inferior adsorption capacity. At the same time, the highest surface area and micropore sites of the AC900 determined a significantly better performance when tested inside the CDI cell. In fact, despite the higher surface area of AC1000 with respect to AC800, the lower amount of micropore sites could determine an inferior adsorption capacity. At the same 
time, the highest surface area and micropore sites of the AC900 determined a significantly better performance when tested inside the CDI cell.

Similar trend regarding specific surface area and adsorption capacity for biomass samples treated at 800,900 and $1000{ }^{\circ} \mathrm{C}$ was found in (Liu et al., 2019) by Liu and his co-workers when testing pine pollen char for capacitive deionization. Authors reported a significant decrease ($38 \%$ ) in specific surface area when the temperature was raised from $900{ }^{\circ} \mathrm{C}$ to $1000{ }^{\circ} \mathrm{C}$, together with a lower ion adsorption. Results from the CDI experiment showed the lowest potential for $\mathrm{NaCl}$ removal for the carbon realized at $1000{ }^{\circ} \mathrm{C}$ while the best result was obtained for the $900{ }^{\circ} \mathrm{C}$ treatment.
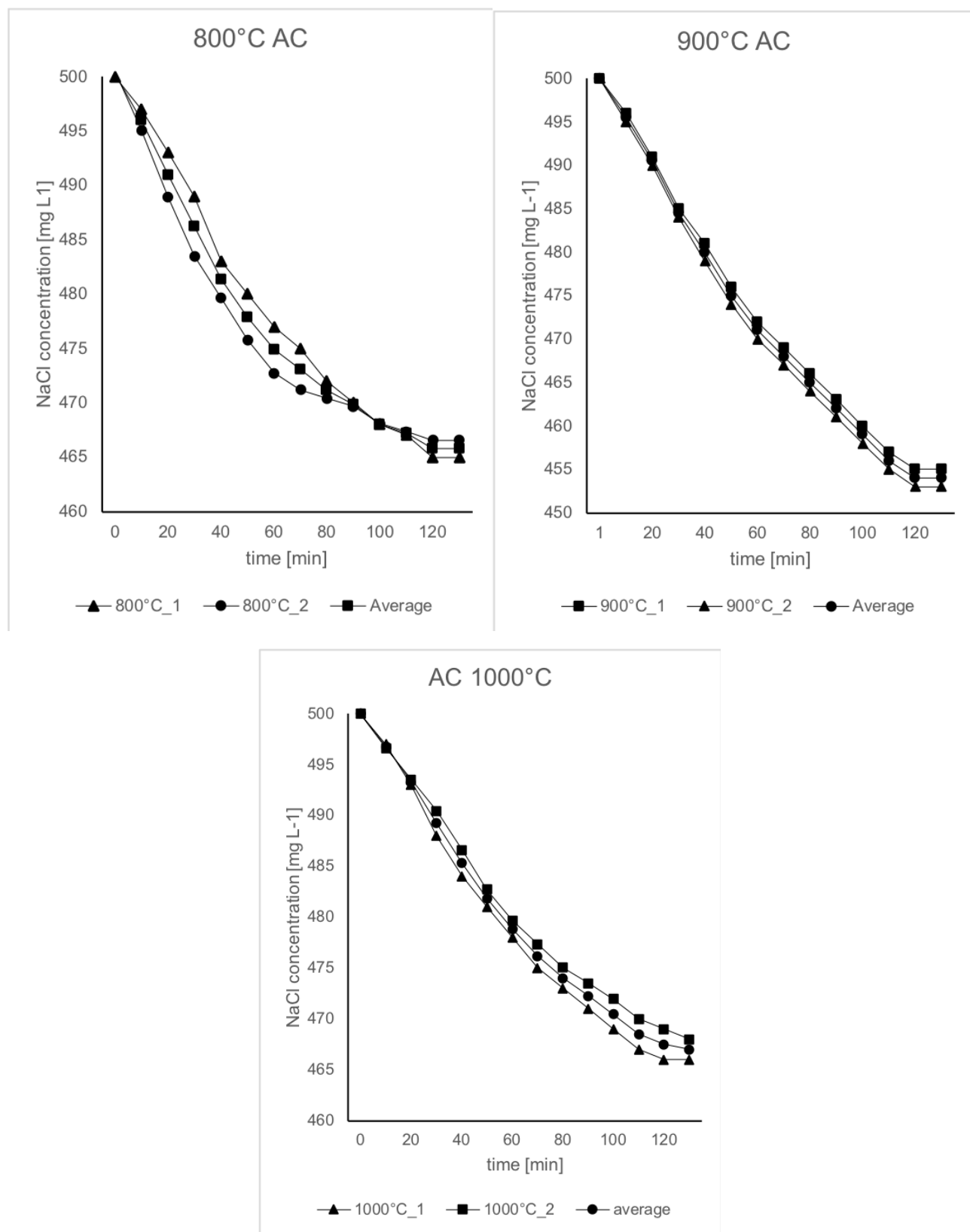

Fig. 6 Results of desalination tests: adsorption capacity 
The adsorption kinetics was studied through the pseudo-first order (eq. 2) (Simonin, 2016) and a pseudo-second (eq. 3) (Robati, 2013) order model, which can be formulated as:

$\ln \left[\frac{q_{e}-q_{t}}{q_{e}}\right]=-k t \quad$ eq. 2

$\frac{t}{q_{t}}=\frac{t}{q_{e}}+\frac{1}{K_{2} * q_{e}^{2}} \quad$ eq. 3

Where $\mathrm{q}_{\mathrm{e}}$ and $\mathrm{q}_{\mathrm{t}}$ are the amount of $\mathrm{NaCl}$ adsorbed (in $\mathrm{mg} \mathrm{g}^{-1}$ ) at time $\mathrm{t}$ and equilibrium, $\mathrm{k}$ and $\mathrm{k}_{2}$ are respectively the first and second order constant of adsorption, and $\mathrm{t}$ is the time. Between the two models, it was selected the one that presents the higher correlation coefficient $\mathrm{R}^{2}$. The values of $\mathrm{R}^{2}$ for the pseudo-first order and pseudo-second order models and for all the three activated carbons are resumed in Tab. 1. It can clearly be seen that the second order kinetic presents a weak correlation for all of the activated carbons, while the first-order fit very well with the data collected from the experiments. Equation 2 was plotted for the three activated carbons and results are reported in Fig. 7.

\begin{tabular}{|c|c|c|}
\hline \multirow[t]{2}{*}{ Sample } & \multicolumn{2}{|r|}{$\mathrm{R}^{2}$} \\
\hline & $1^{\text {st }}$ order & $2^{\text {nd }}$ order \\
\hline AC800 & 0.97 & 0.57 \\
\hline AC900 & 0.91 & 0.67 \\
\hline AC1000 & 0.91 & 0.84 \\
\hline
\end{tabular}

Tab1. Pseudo-first and pseudo-second order kinetic correlation coefficient 


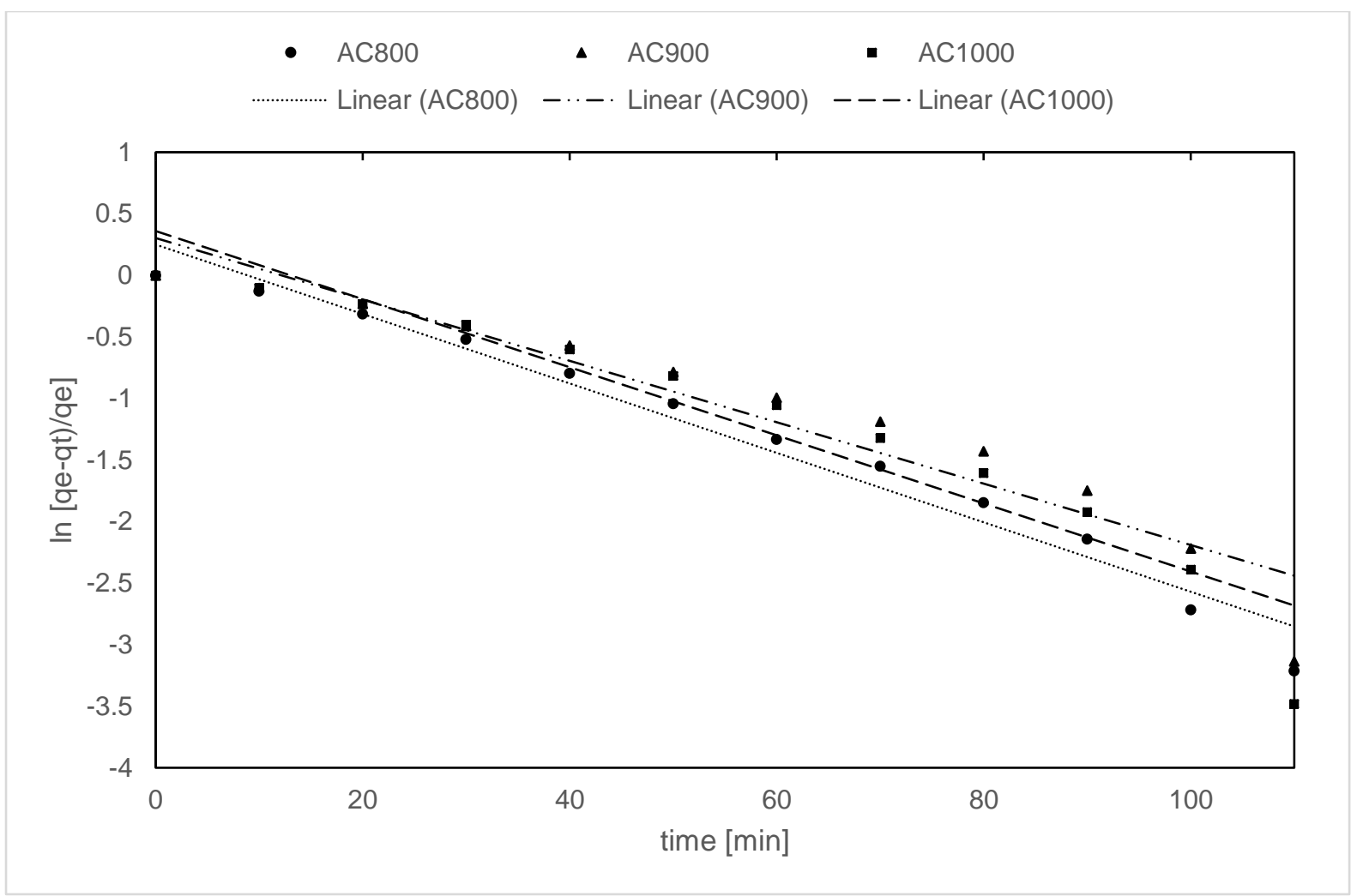

Fig. 7. Pseudo-first order kinetics

The saturated electrodes were further studied through SEM/EDS and TEM/EDS analysis. For the $\mathrm{Na}^{+}$saturated electrode, when evaluating the external composition through a SEM/EDS analysis, there was found an increase in the sodium concentration when inspecting the main outer pores of the material with sodium concentration raising up to $4.03 \%(\mathrm{w} / \mathrm{w})$ from the starting value of $1.76 \%$ obtained during the surveys on AC1000.

\section{Perspective, applications and future works}

Even if numerous researches has been conducted over the last years on CDI, the present technology is still far away from a possible industrial scale application. The main aspects on which the scientific community is working on are the development of a proper carbon internal structure, the reduction of losses inside the cell and the energy recovery from the electrode regeneration step. An appropriate electrode hierarchical porosity can enhance the velocity and the electrosorption capacity, promoting the fluid diffusion inside the material and the ion storage in the micropore sites. Regarding the energy recovery processes, two pioneering works was proposed by García-Quismondo and his research group (García-Quismondo et al., 2013) and by Dlugolęcki et al., (Długołecki and Van Der Wal, 2013). In this latter work, thanks to the optimization of the electrode regeneration step, authors were able to reduce the energy 
consumption up to $0.26 \mathrm{kWh} \mathrm{m}^{-3}$ for a brackish water desalination system, making it competitive with the traditional processes.

Aside from the traditional application in deionization systems, the possibility of coupling CDI with renewable energy sources and the easily scalable dimension of the plant, makes this technology suitable even for the installation in remote locations or developing countries (Mossad et al., 2013). Different studies was conducted to verify such hypothesis running small plants, even in an off-grid condition. These consideration could make CDI an optimal solution for isolated villages who have only access to brackish water sources and no direct connection to the electric grid. Tang and his research group (Tan et al., 2018) studied the possible connection of a $5 \mathrm{~m}^{3}$ day $^{-1}$ membrane capacitive deionization plant to a photovoltaic plant to furnish the energy needed. Another technical solution based on renewable energy sources, has been proposed by Forrestal et al., (Forrestal et al., 2012) who studied the possible use of a CDI system fuelled by a microbial cell. Authors were able to satisfy the energy need, obtaining also significative results in terms of total dissolved solid removal.

It could also be useful to broader the present research to analyse more in depth the transition from the activation temperature of $900^{\circ} \mathrm{C}$ to $1000^{\circ} \mathrm{C}$, since within this range seems to happen the more evident modifications inside the char particles. At the same time, evaluating how the activation time affect the final material could drive to a proper procedure to obtain the best adsorption capacity from the starting biomass sample.

A further study is in progress at the moment, trying to couple crystallography analysis, with ion adsorption capacity. In order to be effective, authors are trying to find various monocrystalline, polycrystalline and amorphous carbon sites to evaluate their Sodium and Chlorine concentrations, in order to define possible adsorption trends in relation to the carbon structure. 


\section{Conclusion}

The evolution of the structure and the adsorption behaviour of three different activated carbon were investigated. Significant changes in the specific surface area and pore size distribution were found when raising the activation temperature from 800 to $1000{ }^{\circ} \mathrm{C}$. Cumulative surface area was found equal to 225, 450 and $316 \mathrm{~m}^{2} \mathrm{~g}^{-1}$ respectively for AC800, AC900 and AC1000. Nevertheless, the adsorption capacity did not follow the same trend, presenting a reduction of $28 \%$, form 19.2 to $13.7 \mathrm{mg} \mathrm{g}^{-1}$, when the activation temperature was increased from 900 to $1000{ }^{\circ} \mathrm{C}$.

\section{Acknowledgements}

Special thanks goes to Dr. Vicente Araullo-Peters for his precious help in the TEM analysis, Mr. Maurizio Leo and all the department of Nanovision from Queen Mary University of London.

\section{References}

AlMarzooqi, F.A., Al Ghaferi, A.A., Saadat, I., Hilal, N., 2014. Application of Capacitive Deionisation in water desalination: A review. Desalination. https://doi.org/10.1016/j.desal.2014.02.031

Anderson, M.A., Cudero, A.L., Palma, J., 2010. Capacitive deionization as an electrochemical means of saving energy and delivering clean water. Comparison to present desalination practices: Will it compete? Electrochim. Acta 55, 3845-3856. https://doi.org/10.1016/J.ELECTACTA.2010.02.012

Belaustegui, Y., Zorita, S., Fernández-Carretero, F., García-Luis, A., Pantò, F., Stelitano, S., Frontera, P., Antonucci, P., Santangelo, S., 2018. Electro-spun graphene-enriched carbon fibres with high nitrogen-contents for electrochemical water desalination. Desalination 428, 40-49. https://doi.org/10.1016/J.DESAL.2017.11.019

Billaud, J., Valin, S., Peyrot, M., Salvador, S., 2016. Influence of H2O, CO2 and O2 addition on biomass gasification in entrained flow reactor conditions: Experiments and modelling. Fuel 166, 166-178. https://doi.org/10.1016/J.FUEL.2015.10.046

Chen, P.-A., Cheng, H.-C., Wang, H.P., 2018. Activated carbon recycled from bitter-tea and palm shell wastes for capacitive desalination of salt water. J. Clean. Prod. 174, 927-932. https://doi.org/10.1016/J.JCLEPRO.2017.11.034 
Chen, Z., Song, C., Sun, X., Guo, H., Zhu, G., 2011. Kinetic and isotherm studies on the electrosorption of $\mathrm{NaCl}$ from aqueous solutions by activated carbon electrodes. Desalination 267, 239-243. https://doi.org/10.1016/J.DESAL.2010.09.033

Chen, Z., Zhang, H., Wu, C., Luo, L., Wang, C., Huang, S., Xu, H., 2018. A study of the effect of carbon characteristics on capacitive deionization (CDI) performance. Desalination 433, 68-74. https://doi.org/10.1016/J.DESAL.2017.11.036

Chérif, M., Mkacher, I., Dammak, L., Ben Salah, A., Walha, K., Grande, D., Nikonenko, V., 2015. Water desalination by neutralization dialysis with ion-exchange membranes: Flow rate and acid/alkali concentration effects. Desalination 361, 13-24. https://doi.org/10.1016/J.DESAL.2015.01.024

D’Anna, A., 2009. Combustion-formed nanoparticles. Proc. Combust. Inst. https://doi.org/10.1016/j.proci.2008.09.005

Debiagi, P.E.A., Gentile, G., Cuoci, A., Frassoldati, A., Ranzi, E., Faravelli, T., 2018. Yield, Composition and Active Surface Area of Char from Biomass Pyrolysis. Chem. Eng. Trans. 65, 97-102 SE-Research Articles. https://doi.org/10.3303/CET1865017

Debiagi, P.E.A., Gentile, G., Pelucchi, M., Frassoldati, A., Cuoci, A., Faravelli, T., Ranzi, E., 2016. Detailed kinetic mechanism of gas-phase reactions of volatiles released from biomass pyrolysis. Biomass and Bioenergy. https://doi.org/10.1016/j.biombioe.2016.06.015

Dehkhoda, A.M., Ellis, N., Gyenge, E., 2016a. Effect of activated biochar porous structure on the capacitive deionization of $\mathrm{NaCl}$ and $\mathrm{ZnCl} 2$ solutions. Microporous Mesoporous Mater. 224, 217-228. https://doi.org/10.1016/J.MICROMESO.2015.11.041

Dehkhoda, A.M., Ellis, N., Gyenge, E., 2014. Electrosorption on activated biochar: Effect of thermo-chemical activation treatment on the electric double layer capacitance. J. Appl. Electrochem. https://doi.org/10.1007/s10800-013-0616-4

Dehkhoda, A.M., Gyenge, E., Ellis, N., 2016b. A novel method to tailor the porous structure of $\mathrm{KOH}$-activated biochar and its application in capacitive deionization and energy storage. Biomass and Bioenergy 87, 107-121. https://doi.org/10.1016/J.BIOMBIOE.2016.02.023

Długołecki, P., Van Der Wal, A., 2013. Energy recovery in membrane capacitive deionization. Environ. Sci. Technol. https://doi.org/10.1021/es3053202 
Dykstra, J.E., Zhao, R., Biesheuvel, P.M., van der Wal, A., 2016. Resistance identification and rational process design in Capacitive Deionization. Water Res. 88, 358-370. https://doi.org/10.1016/J.WATRES.2015.10.006

El-Deen, A.G., Barakat, N.A.M., Khalil, K.A., Kim, H.Y., 2014. Hollow carbon nanofibers as an effective electrode for brackish water desalination using the capacitive deionization process. New J. Chem. https://doi.org/10.1039/c3nj00576c

Feng, C., Chen, Y.-A., Yu, C.-P., Hou, C.-H., 2018. Highly porous activated carbon with multi-channeled structure derived from loofa sponge as a capacitive electrode material for the deionization of brackish water. Chemosphere 208, 285-293. https://doi.org/10.1016/J.CHEMOSPHERE.2018.05.174

Forrestal, C., Xu, P., Ren, Z., 2012. Sustainable desalination using a microbial capacitive desalination cell. Energy Environ. Sci. https://doi.org/10.1039/c2ee21121a

Frenklach, M., Mebel, A.M., 2020. On the mechanism of soot nucleation. Phys. Chem. Chem. Phys. 22, 5314-5331. https://doi.org/10.1039/D0CP00116C

Fukuyama, K., Kasahara, Y., Kasahara, N., Oya, A., Nishikawa, K., 2001. Small-angle X-ray scattering study of the pore structure of carbon fibers prepared from a polymer blend of phenolic resin and polystyrene. Carbon N. Y. https://doi.org/10.1016/S00086223(00)00159-7

García-Quismondo, E., Santos, C., Lado, J., Palma, J., Anderson, M.A., 2013. Optimizing the energy efficiency of capacitive deionization reactors working under real-world conditions. Environ. Sci. Technol. https://doi.org/10.1021/es4021603

Guizani, C., Haddad, K., Limousy, L., Jeguirim, M., 2017. New insights on the structural evolution of biomass char upon pyrolysis as revealed by the Raman spectroscopy and elemental analysis. Carbon N. Y. 119, 519-521. https://doi.org/10.1016/J.CARBON.2017.04.078

Hoekstra, J., Beale, A.M., Soulimani, F., Versluijs-Helder, M., Geus, J.W., Jenneskens, L.W., 2015. Base metal catalyzed graphitization of cellulose: A combined Raman spectroscopy, temperature-dependent X-ray diffraction and high-resolution transmission electron microscopy study. J. Phys. Chem. C. https://doi.org/10.1021/acs.jpcc.5b00477

Hou, C.-H., Liu, N.-L., Hsi, H.-C., 2015. Highly porous activated carbons from resourcerecovered Leucaena leucocephala wood as capacitive deionization electrodes. 
Chemosphere 141, 71-79. https://doi.org/10.1016/J.CHEMOSPHERE.2015.06.055

Huyskens, C., Helsen, J., de Haan, A.B., 2013. Capacitive deionization for water treatment: Screening of key performance parameters and comparison of performance for different ions. Desalination 328, 8-16. https://doi.org/10.1016/J.DESAL.2013.07.002

Kennedy, L.J., Vijaya, J.J., Sekaran, G., 2005. Electrical conductivity study of porous carbon composite derived from rice husk. Mater. Chem. Phys. 91, 471-476. https://doi.org/10.1016/J.MATCHEMPHYS.2004.12.013

Lado, J.J., Zornitta, R.L., Calvi, F.A., Martins, M., Anderson, M.A., Nogueira, F.G.E., Ruotolo, L.A.M., 2017. Enhanced capacitive deionization desalination provided by chemical activation of sugar cane bagasse fly ash electrodes. J. Anal. Appl. Pyrolysis 126, 143-153. https://doi.org/10.1016/J.JAAP.2017.06.014

Li, G.-X., Hou, P.-X., Zhao, S.-Y., Liu, C., Cheng, H.-M., 2016. A flexible cotton-derived carbon sponge for high-performance capacitive deionization. Carbon N. Y. 101, 1-8. https://doi.org/10.1016/J.CARBON.2015.12.095

Li, Y., Jiang, Y., Wang, T.-J., Zhang, C., Wang, H., 2017. Performance of fluoride electrosorption using micropore-dominant activated carbon as an electrode. Sep. Purif. Technol. 172, 415-421. https://doi.org/10.1016/J.SEPPUR.2016.08.043

Liu, Q., Li, X., Wu, Y., Qing, M., Tan, G., Xiao, D., 2019. Pine pollen derived porous carbon with efficient capacitive deionization performance. Electrochim. Acta 298, 360-371. https://doi.org/10.1016/J.ELECTACTA.2018.12.072

Lua, A.C., Guo, J., 2001. Microporous oil-palm-shell activated carbon prepared by physical activation for gas-phase adsorption. Langmuir. https://doi.org/10.1021/la010290c

Martínez, M.L., Torres, M.M., Guzmán, C.A., Maestri, D.M., 2006. Preparation and characteristics of activated carbon from olive stones and walnut shells. Ind. Crops Prod. 23, 23-28. https://doi.org/10.1016/J.INDCROP.2005.03.001

Mossad, M., Zhang, W., Zou, L., 2013. Using capacitive deionisation for inland brackish groundwater desalination in a remote location. Desalination. https://doi.org/10.1016/j.desal.2012.05.021

Oren, Y., 2008. Capacitive deionization (CDI) for desalination and water treatment — past, present and future (a review). Desalination 228, 10-29. https://doi.org/10.1016/J.DESAL.2007.08.005 
Pallarés, J., González-Cencerrado, A., Arauzo, I., 2018. Production and characterization of activated carbon from barley straw by physical activation with carbon dioxide and steam. Biomass and Bioenergy. https://doi.org/10.1016/j.biombioe.2018.04.015

Porada, S., Zhao, R., van der Wal, A., Presser, V., Biesheuvel, P.M., 2013. Review on the science and technology of water desalination by capacitive deionization. Prog. Mater. Sci. 58, 1388-1442. https://doi.org/10.1016/J.PMATSCI.2013.03.005

Qin, K., Jensen, P.A., Lin, W., Jensen, A.D., 2012. Biomass gasification behavior in an entrained flow reactor: Gas product distribution and soot formation. Energy and Fuels. https://doi.org/10.1021/ef300960x

Robati, D., 2013. Pseudo-second-order kinetic equations for modeling adsorption systems for removal of lead ions using multi-walled carbon nanotube. J. Nanostructure Chem. 3, 55. https://doi.org/10.1186/2193-8865-3-55

Rodriguez-Reinoso, F., Molina-Sabio, M., Muñecas, M.A., 1992. Effect of microporosity and oxygen surface groups of activated carbon in the adsorption of molecules of different polarity. J. Phys. Chem. https://doi.org/10.1021/j100185a056

Simonin, J.P., 2016. On the comparison of pseudo-first order and pseudo-second order rate laws in the modeling of adsorption kinetics. Chem. Eng. J. https://doi.org/10.1016/j.cej.2016.04.079

Tan, C., He, C., Tang, W., Kovalsky, P., Fletcher, J., Waite, T.D., 2018. Integration of photovoltaic energy supply with membrane capacitive deionization (MCDI) for salt removal from brackish waters. Water Res. https://doi.org/10.1016/j.watres.2018.09.056

Valdés, C.F., Betancur, Y., López, D., Gómez, C.A., Chejne, F., 2018. Effects of pyrolysis atmosphere on the porous structure and reactivity of chars from middle and high rank coals. Ing. e Investig. https://doi.org/10.15446/ing.investig.v38n1.64516

Volpe, R., Menendez, J.M.B., Reina, T.R., Messineo, A., Millan, M., 2017. Evolution of chars during slow pyrolysis of citrus waste. Fuel Process. Technol. 158, 255-263. https://doi.org/10.1016/J.FUPROC.2017.01.015

Volpe, R., Messineo, A., Millan, M., Volpe, M., Kandiyoti, R., 2015. Assessment of olive wastes as energy source: Pyrolysis, torrefaction and the key role of $\mathrm{H}$ loss in thermal breakdown. Energy. https://doi.org/10.1016/j.energy.2015.01.011

Wang, X., Bai, S., Jin, Q., Li, S., Li, Yukun, Li, Yan, Tan, H., 2018. Soot formation during 
biomass pyrolysis: Effects of temperature, water-leaching, and gas-phase residence time. J. Anal. Appl. Pyrolysis. https://doi.org/10.1016/j.jaap.2018.07.015

Wang, Y., Chung, S.H., 2019. Soot formation in laminar counterflow flames. Prog. Energy Combust. Sci. https://doi.org/10.1016/j.pecs.2019.05.003

Welgemoed, T.J., Schutte, C.F., 2005. Capacitive Deionization Technology ${ }^{\mathrm{TM}}$ : An alternative desalination solution. Desalination. https://doi.org/10.1016/j.desal.2005.02.054

Yu, J., Lucas, J.A., Wall, T.F., 2007. Formation of the structure of chars during devolatilization of pulverized coal and its thermoproperties: A review. Prog. Energy Combust. Sci. https://doi.org/10.1016/j.pecs.2006.07.003

Zabaniotou, A., Stavropoulos, G., Skoulou, V., 2008. Activated carbon from olive kernels in a two-stage process: Industrial improvement. Bioresour. Technol. 99, 320-326. https://doi.org/10.1016/J.BIORTECH.2006.12.020

Zarzo, D., Prats, D., 2018. Desalination and energy consumption. What can we expect in the near future? Desalination. https://doi.org/10.1016/j.desal.2017.10.046

Zhang, D., Shi, L., Fang, J., Dai, K., 2007. Influence of diameter of carbon nanotubes mounted in flow-through capacitors on removal of $\mathrm{NaCl}$ from salt water. J. Mater. Sci. https://doi.org/10.1007/s10853-006-1293-z

Zhang, T., Walawender, W.P., Fan, L.T., Fan, M., Daugaard, D., Brown, R.C., 2004. Preparation of activated carbon from forest and agricultural residues through $\mathrm{CO} 2$ activation. Chem. Eng. J. 105, 53-59. https://doi.org/10.1016/J.CEJ.2004.06.011

Zhang, Y., Chen, L., Mao, S., Sun, Z., Song, Y., Zhao, R., 2019. Fabrication of porous graphene electrodes via $\mathrm{CO} 2$ activation for the enhancement of capacitive deionization. J. Colloid Interface Sci. 536, 252-260. https://doi.org/10.1016/J.JCIS.2018.10.063 